\title{
Evaluation of Goat Fat as Potential Co-Lubricant in Pharmaceutical Tablet Dosage Form
}

\author{
Dr. S. O. Majekodunmi* ${ }^{1}$ and ${ }^{2}$ E.B. Matthew \\ ${ }_{1,2}$ Department of Pharmaceutics and Pharmaceutical Technology, Faculty of Pharmacy, University of \\ Uyo, Uyo, Nigeria.
}

\begin{abstract}
In this study, goat fat co-processed with a combination of magnesium stearate and talc (GMT) was evaluated as a lubricant and compared with magnesium stearate plus talc (MT) and without lubricant using flow of granules, mechanical properties of tablets of crushing strength, the disintegrant properties of tablet disintegration time (DT) and crushing strength friability/disintegration time ratio $(C S F R / D T)$ as assessment parameters. Granules were lubricated with different concentrations of $0.5 \% \mathrm{w} / \mathrm{w}$, $1.5 \% \mathrm{w} / \mathrm{w}, 2.0 \% \mathrm{w} / \mathrm{w}$ and $2.5 \% \mathrm{w} / \mathrm{w}$ of the co-processed lubricant of goat fat, magnesium stearate and talc (GMT) and combination of magnesium stearate and talc (MT) and without lubricant in a paracetamol tablet formulation. The flow of the granules quantified as Hausner ratio, Carr's index, and angle of repose showed that granules lubricated with the co-processed lubricant of goat fat (GMT) improved the flow properties of paracetamol granules compared to granules lubricated with magnesium stearate and talc alone. The tablet properties of paracetamol prepared from granules lubricated with GMT were comparable with tablets prepared from granules lubricated with $M T$ and without lubricant. The tablets produced by GMT possessed acceptable crushing strength, friability and disintegration time and thus CSFR/DT. The study shows that the lubricant type and concentration influenced the crushing strength and disintegration time of the tablets and the co-processed lubricant could also be useful in situations where a low crushing strength friability/ disintegration (CSFR/DT) value is required, such as sustained release tablet.
\end{abstract}

KEYWORDS: Goat fat, Magnesium stearate, Talc, Crushing strength, Disintegration time, Tablet.

\section{INTRODUCTION:}

Tablet lubricants are those excipients added to the tablet formulation which would help tablet to easily eject from the die cavity and would prevent sticking of tablet to die cavity as well. Without tablet lubricants tablets cannot be produced. However some confusion exits in the definition of a lubricant because glidants, anti-adherents perform the same function. These interrelated groups of tablet excipients are used in tablet production to promote granule flow, prevent powder adhesion to punch faces and minimize die wall friction respectively [1]. This means that a lubricant can form the purpose of the three groups of excipients. A lubricant can also be defined as a suitable material in small amount of which interpose between two rubbing surfaces to reduce friction at the interface [2], [3]. An ideal lubricant should be inert and water soluble, colourless, odourless. A lubricant should be capable of reducing wear on rubbing surfaces ([4]. To perform this function the lubricant must provide film that will prevent solid to solid contact, and is easily sheared. A given lubricant may provide one or more of these actions to varying degrees but no one material is highly efficient in all categories [5], [6]. Thus, combination of lubricants is often selected to provide the necessary total lubricant effect [6].

Goat fat, obtained from goats (Capra hircus), is a cheap and readily available semisolid fatty substance because hundreds of goats are on daily basis slaughtered in Nigeria, Goat fat contains lipid-oily and fatty substances- by their nature exert lubricity over surfaces encountered with. It is therefore that when applied in carefully regulated amount they will improve the lubrication efficiency in lubricants used in tableting. Lipids have been studied for their effects on the characteristics of granules and tablets such as moisture content, tablet hardness, disintegration and dissolution, and the stability of active ingredients. N'Daiye et al. [7] and Aoshima et al. [8] showed that lipids have no negative effect on tablet hardness. Aoshima et al. [8], further showed that unlike magnesium stearate which delays disintegration and dissolution of the active ingredient [9], [10], [11], the fatty acid esters promotes a reduction in disintegration time. They concluded that the fatty acid esters are superior to magnesium stearate because the tablets containing them have better stability and are free of biological problems such as viral contamination, which may be due to the very low moisture content of the granules containing the fatty acid esters compared with those of other lubricants. Hence, the purpose of this work was to co-process goat fat with a 50:50 mixture of magnesium stearate and talc (MT) in a paracetamol formulation, and to evaluate 
the influence of the changes in the concentration of lubricant on the disintegrant properties of tablets produced. This study could provide relevant information on the lubricant activity of goat fat on disintegration of tablets.

Disintegrant properties are determined by measuring disintegration time and correlation with the friability and crushing strength of tablets. These parameters will then be used to quantify the crushing strength-friability/disintegration time (CSFR/DT) of the tablets. The CSFR/DT is used for evaluating the balance between the binding and disintegration properties of a tablet

In this present work, Goat fat is co-processed with 50:50 mixture of magnesium stearate and talc. Thus, the aim of this study was to co-process goat fat with 50-50 mixture of magnesium stearate and talc using the flow properties and disintegration time test of a paracetamol tablet formulation as assessment parameters. Hausner ratio, Carr's index, and angle of repose were used to analyze the flow properties of the granules.

\section{MATERIALS AND METHODS}

The materials used were paracetamol B P, corn starch BP and benzene (BDH Chemicals Ltd, Poole, UK); lactose BP (AB Knight and Co, London, UK); goat fat, magnesium stearate and talc (Merck KGA, Darmstadt, Germany), Ethanol (Sigma-Aldrich Laborchemikalien GMBH, Seelze, Germany). All other chemicals and reagents were of analytical grade.

\subsection{Extraction of goat (Capra hircus) fat}

The fat was extracted from the adipose tissue of goat (Capra hircus) skin by wet rendering. The extraneous materials were manually separated from the adipose tissue which was then rendered by the wet process. The adipose tissue was grated and subjected to moist heat by boiling with half its weight of water in a water bath for 45 minutes. The molten fat was separated from the aqueous phase by filtration with a muslin cloth.

\subsection{Co-processing of magnesium stearate-talc mixture with goat fat}

Goat fat $(2.0 \mathrm{~g})$ was placed inside a beaker containing $50 \mathrm{~mL}$ of $95 \%$ absolute ethanol. This was then placed in a water bath set at $60^{\circ} \mathrm{C}$ to allow for the melting and dissolving of goat fat in the ethanol. Magnesium stearate-talc mixture (MT) $(10 \mathrm{~g})$ was added and mixed with the ethanolic solution of goat fat in the beaker. The ethanol was allowed to evaporate from the mixture. The mixture (GMT) was placed in the dessicator for $72 \mathrm{hrs}$ to allow for the ethanol to evaporate. The processed mixture was then stored in a screw-capped bottle until needed.

\subsection{Preparation of magnesium strearate / talc lubricant mixture}

Equal amounts of magnesium stearate and talc powders were triturated together using a porcelain mortal and pestle for a period of $5 \mathrm{~min}$ to ensure a uniform mixing of the two powders. The binary mixture (MT) was sieved with a 120 mesh sieve $(125 \mu \mathrm{m})$ and then stored in a screw-capped bottle until needed.

2.4 Preparation of binder mucilage

Starch mucilage was prepared by suspending $75 \mathrm{~g}$ of corn starch in $150 \mathrm{~mL}$ of distilled water. This was heated on a Bunsen burner with continuous stirring until mucilage was formed. The mucilage was used while still hot for more effective binding.

\subsection{Preparation of granules}

Batches $(600 \mathrm{~g})$ of a basic formula of drug $(85 \%)$, lactose $(10 \%)$ and corn starch $(5 \%)$ were driedmixed for $5 \mathrm{~min}$. using mortar and pestle and then moistened with the starch mucilage to produce granules. Massing was continued for $5 \mathrm{~min}$. and the wet masses were granulated by passing them manually through a no. $4 \mathrm{~mm}$ mesh sieve and dried in hot air oven (P-Selecta 0384635; China) for $24 \mathrm{hrs}$ at $60^{\circ} \mathrm{C}$. The dried granules $(20 \%)$ were further passed through a $1.0 \mathrm{~mm}$ mesh size and the remainders $(80 \%)$ through a $2 \mathrm{~mm}$ mesh size and both granules were mixed together. The same was carried out to obtain eight different batches.

\subsection{Evaluation of granule properties}

\subsubsection{Moisture content and particle density}

Moisture content of the batches was determined with an Ohaus moisture balance (Ohaus Scale Corporation, USA) while the particle density determined by the pycnometer method using xylene as the displacement fluid. 


\subsubsection{Flow rate}

A plastic funnel was placed in a ring and supported with a retort stand. A clean white sheet of paper was placed below the assembly such that the distance between the white paper on the bench and the funnel orifice was $10 \mathrm{~cm}$ for the batches. Quantity $(30 \mathrm{~g})$ of each batch was weighed using an electronic balance (DT-500A, India). The funnel orifice was covered with a shutter and the granules weighed for each batch was transferred into the funnel. The shutter was removed simultaneously as the timer started. The time taken for all the granules to pass through the funnel orifice was recorded. The same was done for other batches. Three different determinations were carried out for the different batches of granules. The amount of granules used was divided by the time taken for the entire granule to fall from the funnel to determine the flow rate.

\subsubsection{Bulk density and tapped density determinations}

Quantity (30g) of each batch of granules was weighed out; each granule was transferred into a $100 \mathrm{ml}$ measuring cylinder and the initial volume was noted which represent the bulk volume. The measuring volume was tapped over a period of time until the volume of the granules remained constant. The volume was recorded and this represented the tapped volume. This was repeated 3 times for the different batches of the granules and the bulk and tapped densities of each batch were calculated from the volume from which the Carr's index and Hausner's ratio were calculated which indicates the flowability of the granule.

\subsubsection{Angle of repose}

The static angle of repose was measured according to the fixed funnel and free standing cone method. Each batch of the granules was carefully poured through the funnel until the apex of the cone formed just reach the tips of the funnel. The mean diameter of the tip of the cone was determined and the tangent of the angle of repose calculated using the following equation.

$\operatorname{Tan} \Theta=2 \mathrm{~h} / \mathrm{D}$ .Eqn. (9)

Where $\mathrm{h}$ is the height of the heap of granule and $\mathrm{D}$ is the diameter of the base of the granule heap.

\subsubsection{Hausner ratio}

This was calculated as a ratio of the tapped density to the bulk density of the granules i.e.

Tapped density / bulk density. ....Eqn. (10)

\subsubsection{Carr's index}

This was computed from the following equation:

$\%$ compressibility $=($ Tapped density- Bulk density $) /$ Tapped density $\mathrm{x} 100$. ...Eqn. (11).

\subsection{Preparation of tablets}

The granules were passed through $1.00 \mathrm{~mm}$ sieve to separate the fine from coarse granules. The fine granules were mixed with magnesium stearate-talc mixture $(0.5 \% \mathrm{w} / \mathrm{w}, 1.5 \% \mathrm{w} / \mathrm{w}, 2.0 \% \% \mathrm{w} / \mathrm{w}$ and $2.5 \% \mathrm{w} / \mathrm{w}$ ), and corn starch (extra granular incorporation), then with coarse granules and mixed thoroughly. The die cavity of the tableting press was set to obtain the maximum weight of the tablet. The hopper was filled with the granules/powder mix and then tableted using a Manesty F3 single punch tableting machine (Model SSF-3) (Cadmach Machinery Co. PVT. Ltd.; India) to compress the granules into tablet at $20 \mathrm{kgf}$ as operating pressure. The same was done for the other batch lubricated with goat fat-magnesium stearatetalc mixture by varying the concentrations as follows: $(0.5 \% \mathrm{w} / \mathrm{w}, 1.5 \% \mathrm{w} / \mathrm{w}, 2.0 \% \mathrm{w} / \mathrm{w}$, and $2.5 \% \mathrm{w} / \mathrm{w})$.

\subsection{Evaluation of tablet properties \\ 2.8.1 Weight uniformity}

Twenty tablets were randomly selected from each batch of the tablet. The tablets were weighed individually using an electronic weighing balance (Model; DT-500A, India) and their weight recorded. The mean weight was calculated. The percentage deviations of each tablet from the mean weight were determined.

\subsubsection{Crushing strength}

One tablet from each batch was held diametrically in the jaws of a tablet hardness tester (Monsanto), India (Model; MHT-20) and the force in kg required to crush each tablet noted. The mean of ten determinations was taken for each batch. 


\subsubsection{Friability test}

Ten tablets from each of the batch were de-dusted, weighed and placed in a separate drum of a Roche friabilator (DT-2D, India). The tablets were then tumbled for $4 \mathrm{~min}$ at a speed of 25 revolutions/min after which they were again de-dusted and weighed again. The friability of the tablet expressed as percentage was obtained from the initial and final weight using the equation below:

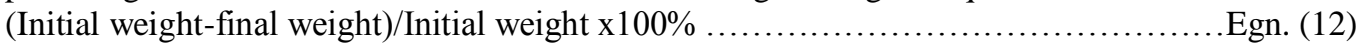

\subsubsection{Disintegration time test}

The disintegration time of the tablets was determined in distilled water at $37 \pm 2^{\circ} \mathrm{C}$ using an Erweka disintegration testing apparatus (Model: Copley ZT2, Euweka Apparatebau GMBH, Heusenstamm, Germany) six tablets randomly selected for each batch were used for the test.

2.8.5 Statistical analysis

Statistical analysis was done using one way ANOVA followed by Duncan's test. The other data were evaluated using Graph Pad Prism software. Data were expressed as mean \pm SD. A p-value $<0.05$ was considered significant.

\section{RESULTS AND DISCUSSION}

\subsection{Physico-chemical properties of granules}

The results of the physic-chemical properties of the granules: particle density (PD), bulk density (BD, Hausner ratio (HR), Carr's Index (CI), angle of repose (AR), moisture content (MC) and \% porosity are presented in Table 3.1. The flow properties of the powder are essential in determining the suitability of a material as a direct compressible excipient. The flow rates of all the granules produced using different concentration of the lubricant were adequate (with range of values between $10.38-12.60$ ) thus they exhibited better flow properties than the batch without lubricant having the value of 8.82 . Generally, for Hausner ratio, values less than 1.25 indicate good flow while values greater than 1.25 indicate poor flow. In our results in Table 3.1, we observed that the granules all had values less than 1.25 (ranging from 1.081.20) indicating good flow and the empirical guide given by Carr's Index (Table 3) values of 5- 10 shows excellent flow, 12-16 for good flow18-21 fair, 23-28 as poor flow, 35- 38 very poor and greater than 40 as extremely poor flow. It was observed that granules had a compressibility index ranging from 8.22 to 16.88 indicating good flow of the granules with batch without lubricant having the highest values. Angle of repose has been an indirect method of quantifying granules' flowability because of relationship with interparticle cohesion. It is possible that different angles of repose could be obtained for some powder owing to differences in the handling of the sample prior to measurement. For this reason angle of repose tend to be variable and are not always representative of the flow under specific condition. Thus it was observed that the granules without lubricant had a value of $35.38^{\circ}$ indicating a passable type of flow, while the granules that were lubricated with different concentrations of the lubricant (magnesium stearate-talc mixture) had good flow with values ranging $26.00^{\circ}-28.86^{\circ}$ and the granules lubricated with the co processed lubricant (GMT) had excellent flow $\left(21.80^{\circ}-25.16^{\circ}\right)$. See appendices 4, 5, 6 and 7 for calculations. The percentage moisture content for granules with goat fat-magnesium stearate-talc is higher than that of granules with magnesium stearate-talc and granules without lubricant having the least percentage of moisture content. This could be due to the hygroscopic nature of goat fat.

\subsection{Crushing strength, friability and disintegration tests}

The results of the crushing strength, friability and disintegration time tests are presented in Table 3.2 , while the representative plots of crushing strength (kgf) versus relative density $\left(\mathrm{g} / \mathrm{cm}^{3}\right)$ for paracetamol tablet containing $0.0 \% \mathrm{w} / \mathrm{w}$ lubricant, $2.5 \% \mathrm{w} / \mathrm{w}$ MT, and $2.5 \% \mathrm{w} / \mathrm{w}$ GMT are presented in Fig. 3.1. The representative plots of friability $(\%)$ versus relative density $\left(\mathrm{g} / \mathrm{cm}^{3}\right)$ for paracetamol tablets containing $0.0 \% \mathrm{w} / \mathrm{w}$ lubricant; $2.5 \% \mathrm{w} / \mathrm{w}$ MT; and $2.5 \% \mathrm{w} /{ }_{\mathrm{w}}$ GMT are presented in Fig. 3.2, while the effects of relative density $\left(\mathrm{g} / \mathrm{cm}^{3}\right)$ on disintegration time for paracetamol tablets containing different concentration of lubricants; $0.5 \% \mathrm{w} / \mathrm{w}, 1.5 \% \mathrm{w} / \mathrm{w}, 2.5 \% \mathrm{w} / \mathrm{w}$ MT and $0.5 \% \mathrm{w} / \mathrm{w}, 1.5 \% \mathrm{w} / \mathrm{w}, 2.5 \% \mathrm{w} / \mathrm{w}$ GMT are presented in Fig. 3.3. The representative plots of CSFR/DT versus relative density $\left(\mathrm{g} / \mathrm{cm}^{3}\right)$ for paracetamol tablets containing $0.0 \% \mathrm{w} / \mathrm{w}$ of lubricant; $2.0 \% \mathrm{w} / \mathrm{w}$ of MT and $2.0 \% \mathrm{w} / \mathrm{w}$ of GMT are presented in Fig. 3.4.

\subsubsection{Crushing strength}

The mechanical strength of tablet dosage forms is an important property and it plays a significant role in product development and manufacturing control. Tablet hardness is the force necessary to cause a tablet to fracture when compressed between two rigid patens [22]. It is affected by the type and concentration of binder, lubricant and compression force. Force (4kgf) is considered minimum for 
Table 3.1: Values of physico-chemical properties of granules

\begin{tabular}{lllllllll}
\hline $\begin{array}{l}\text { Lubr } \\
\text { icant }\end{array}$ & $\%^{\mathbf{w}} / \mathbf{w}$ & PD & BD & HR $(\mathbf{\pm S D})$ & $\begin{array}{c}\text { CI } \\
(\boldsymbol{\%})( \pm \text { SD) }\end{array}$ & AR $( \pm$ SD) & $\begin{array}{l}\text { MC } \\
(\%)\end{array}$ & $\begin{array}{l}\text { \% } \\
\text { Porosity }\end{array}$ \\
\hline None & 0.0 & 1.410 & 0.566 & $1.19(0.01)$ & $16.88(0.02)$ & $35.38(0.02)$ & 1.21 & 59.85 \\
MT & 0.5 & 1.422 & 0.594 & $1.12(0.02)$ & $12.77(0.02)$ & $26.00(0.05)$ & 1.38 & 58.22 \\
& 1.5 & 1.436 & 0.545 & $1.15(0.02)$ & $14.58(0.02)$ & $27.24(0.02)$ & 1.41 & 62.04 \\
& 2.0 & 1.470 & 0.625 & $1.06(0.01)$ & $8.21(0.01)$ & $26.56(0.02)$ & 1.48 & 57.48 \\
& 2.5 & 1.499 & 0.566 & $1.14(0.02)$ & $14.99(0.01)$ & $28.86(0.04)$ & 1.50 & 62.24 \\
GMT & 0.5 & 1.502 & 0.566 & $1.12(0.02)$ & $13.18(0.02)$ & $25.16(0.02)$ & 1.80 & 62.31 \\
& 1.5 & 1.510 & 0.555 & $1.12(0.01)$ & $13.10(0.01)$ & $23.72(0.02)$ & 1.86 & 63.24 \\
& 2.0 & 1.522 & 0.597 & $1.09(0.02)$ & $10.34(0.01)$ & $23.96(0.04)$ & 1.87 & 60.77 \\
& 2.5 & 1.515 & 0.526 & $1.15(0.02)$ & $15.83(0.01)$ & $21.80(0.02)$ & 2.02 & 65.28 \\
\hline
\end{tabular}

MT = Magnesium stearate and Talc, GMT= Goat fat, Magnesium Stearate and Talc, $\mathbf{P D}=$ particle density, $\mathrm{BD}=$ Bulk density, $\mathrm{HR}=$ Hausner ratio, $\mathrm{CI}=$ Carrs index, $\mathrm{AR}=$ Angle of repose, $\mathrm{MC}=$ Moisture content

Table 3.2: Values of crushing strength (CS), Disintegration time (DT), Friability (FR) and crushing strength-friability/disintegration time ratio (CSFR/DT) of paracetamol tablets.

\begin{tabular}{llllll}
\hline Lubricant & Conc. $(\%$ w/w) & CS (Kgf) & FR $(\%)$ & DT (min) & CSFR/DT \\
\hline None & 0.0 & 7.1 & 1.21 & 2.17 & 2.704 \\
MT & 0.5 & 5.7 & 1.06 & 1.16 & 4.635 \\
& 1.5 & 5.8 & 0.82 & 1.23 & 5.750 \\
& 2.0 & 6.1 & 0.78 & 1.32 & 5.924 \\
GMT & 2.5 & 6.5 & 0.66 & 1.70 & 5.793 \\
& 0.5 & 6.3 & 1.13 & 1.86 & 2.997 \\
& 1.5 & 6.4 & 1.19 & 1.90 & 2.830 \\
& 2.0 & 6.5 & 1.20 & 2.03 & 2.668 \\
\hline
\end{tabular}

MT = Magnesium stearate and Talc, GMT= Goat fat, Magnesium Stearate and Talc CS = Crushing strength, $\mathbf{F R}=$ Friability, $\mathbf{D T}=$ Disintegration time CSFR/DT = Crushing strength friability/ disintegration time ratio 


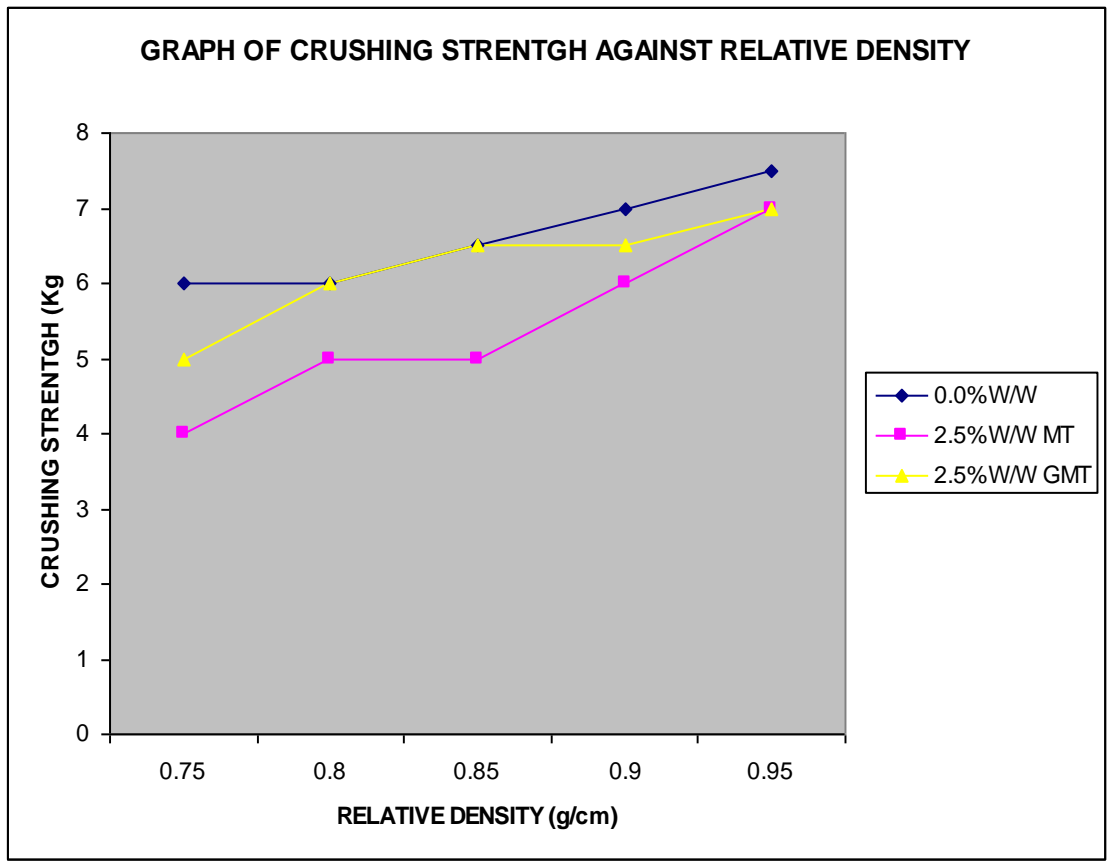

Fig. 3.1: Representative plot of crushing strength (kgf) versus relative Density $\left(\mathrm{g} / \mathrm{cm}^{3}\right)$ for paracetamol tablet containing $0.0 \% \mathrm{w} / \mathrm{w}$ lubricant, $2.5 \% \mathrm{w} / \mathrm{w}$ MT and $2.5 \% \mathrm{w} / \mathrm{w}$ GMT.

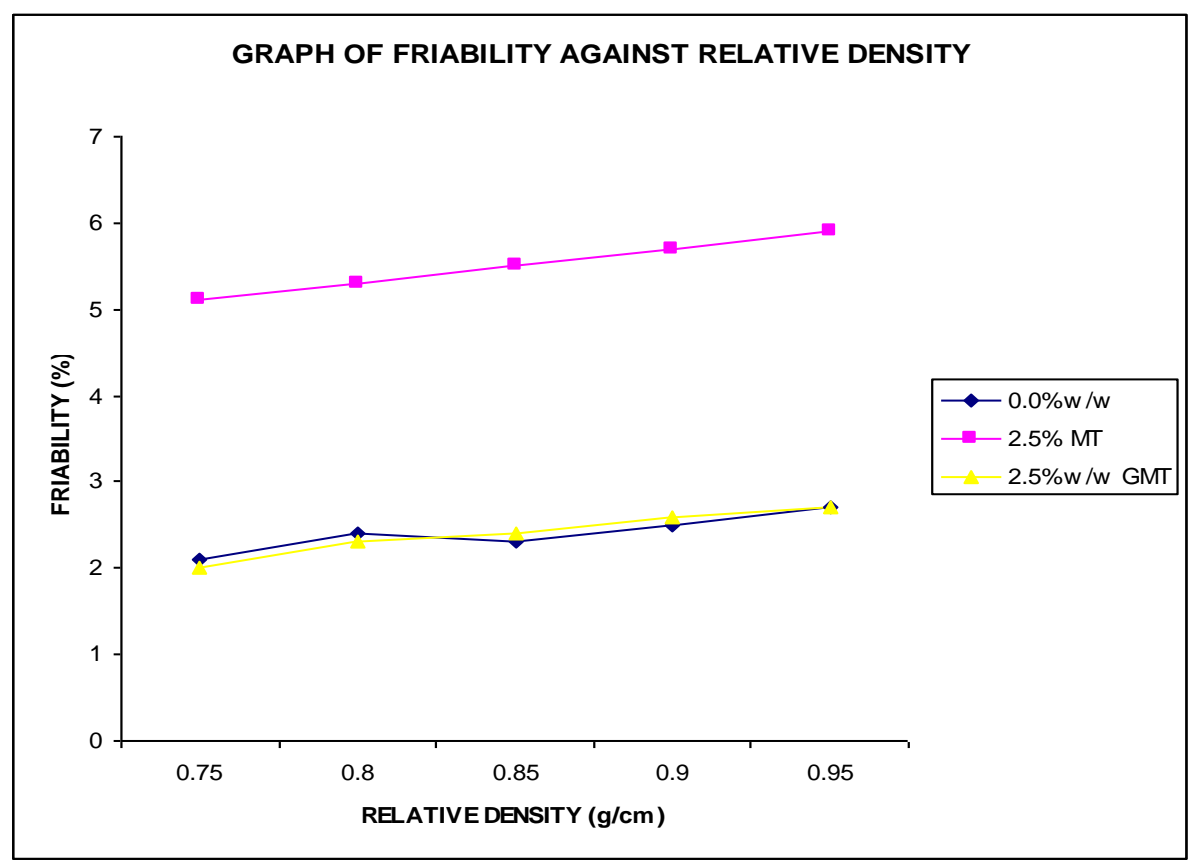

Fig. 3.2: Representative plots of friability $(\%)$ versus relative density $\left(\mathrm{g} / \mathrm{cm}^{3}\right)$ for paracetamol tablets containing $0.0 \% \mathrm{w} / \mathrm{w}$ lubricant; $2.5 \% \mathrm{w} / \mathrm{w} \mathrm{MT}$; and $2.5 \% \mathrm{w} / \mathrm{w}$ GMT 


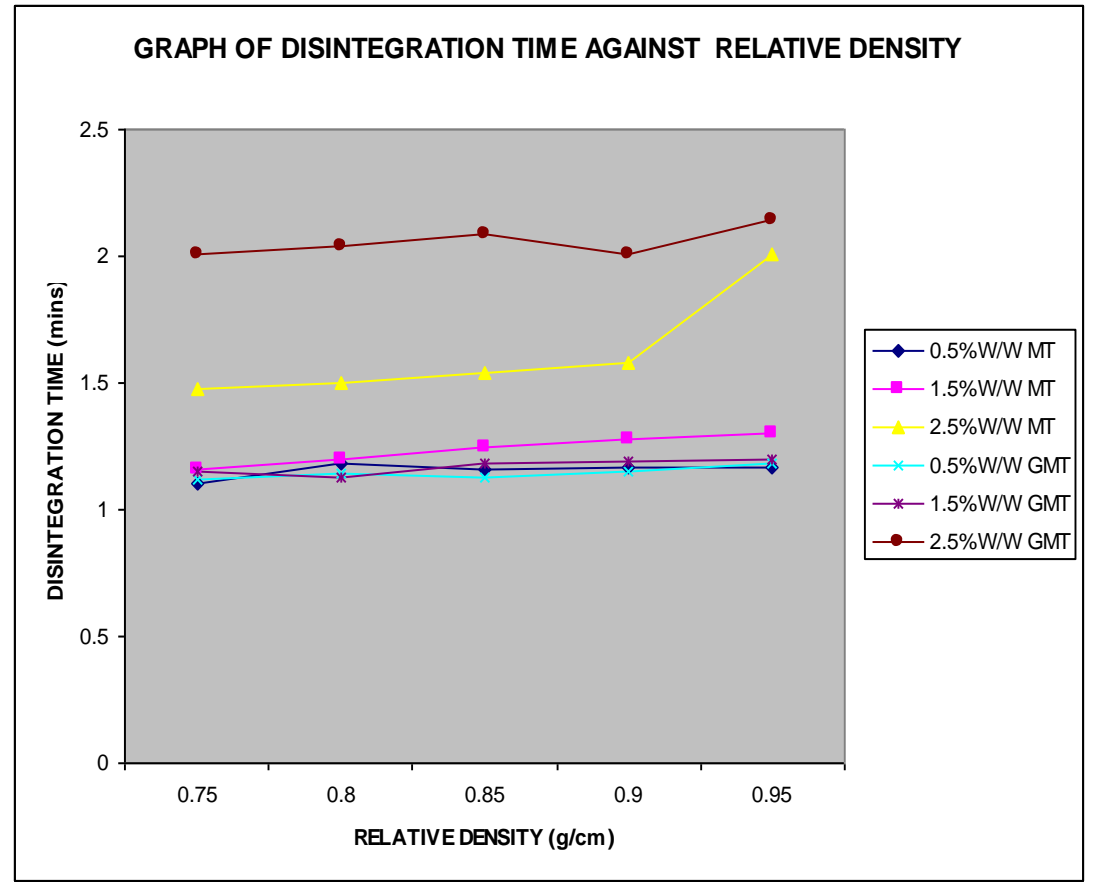

Fig. 3.3: Effects of relative density $\left(\mathrm{g} / \mathrm{cm}^{3}\right)$ on disintegration time for paracetamol tablets containing different concentration of lubricants: $0.5 \% \mathrm{w} / \mathrm{w}, 1.5 \% \mathrm{w} / \mathrm{w}, 2.5 \% \mathrm{w} / \mathrm{w}$ MT and $0.5 \% \mathrm{w} / \mathrm{w}, 1.5 \% \mathrm{w} / \mathrm{w}_{\mathrm{w}}, 2.5 \% \mathrm{w} / \mathrm{w}$ GMT.

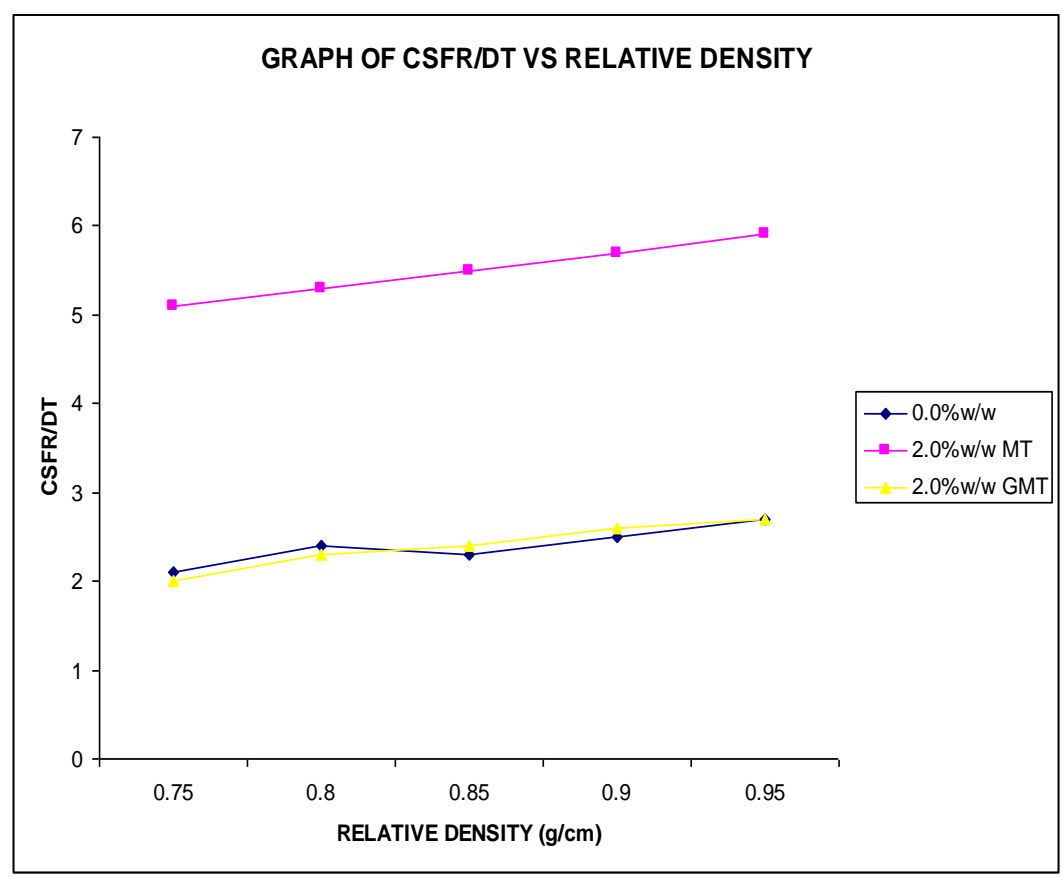

Fig. 3.4: Representative plots of CSFR/DT versus relative density $\left(\mathrm{g} / \mathrm{cm}^{3}\right)$ for paracetamol tablets containing $0.0 \% \mathrm{w} / \mathrm{w}$ of lubricant, $2.0 \% \mathrm{w} / \mathrm{w}$ of MT and $2.0 \% \mathrm{w} / \mathrm{w}$ of GMT 
satisfactory tablet [23]. Crushing strength results obtained for all the nine batches of tablet produced had acceptable hardness values with mean ranging from 7.1 - $6.8 \mathrm{kgf}$ (Table 5). It was observed that as the concentration of the lubricant increases, the hardness increases for the batches lubricated with magnesium stearate-talc as lubricant and for the batches lubricated with goat fat-magnesium stearate-talc mixture with a higher crushing strength. This could be as a result of altered physical properties caused by the lubricant that created a waxy covering and prohibited inter-particulate forces from bonding, and since the goat fat is semi-solid there were more particle-particle contact points. Figure 1.shows representative plots of the crushing strength versus relative density of paracetamol tablets at a concentration of $0.0 \% \mathrm{w} / \mathrm{w}$ and $2.5 \% \mathrm{w} / \mathrm{w}$ lubricant mixtures. It can be observed that the relative density had an effect on the crushing strength of the tablet, thus increasing the relative density lead to an increase in the crushing strength of the tablet with magnesium stearate-talc, and tablet with goat fat - magnesium stearate-talc mixture.

\subsubsection{Friability}

Tablet must be hard enough to withstand the agitation and stress that occur during manufacturing, coating, packaging, shipping and patient use; but must be friable enough to break up when swallowed. Tablets that remain intact without cracking or chopping e.g. (less than $1 \%$ weight change) typically have sufficient strength to withstand fewer processing and packaging [23] (Martins, 2006). From the results obtained in Table 5 it can be seen that as the concentration of the lubricants increases, the tablet with magnesium stearate-talc mixture as lubricant had their friability decreases, while for tablet lubricated with goat fat-magnesium stearate-talc mixture, the friability was observed to increase with increase in lubricant concentration. Also from the representative plot of friability versus relative density for the paracetamol tablet containing lubricant at the concentration of $0.0 \% \mathrm{w} / \mathrm{w}, 2.5 \% \mathrm{w} / \mathrm{w}$ magnesium stearate-talc mixture the friability values decreased with increase in relative density, while for $2.5 \% \mathrm{w} / \mathrm{w}$ goat fat-magnesium stearate-talc the friability values increased with an increase in relative density. This observation could be due to the influence of forces of attraction in the tablet mass.

\subsubsection{Disintegration time}

The disintegration time of the paracetamol tablet obtained in Table 3.2 generally showed an increase with the increase in lubricant concentration with tablets lubricated with goat fat-magnesium stearate-talc (GMT) mixture showing a higher disintegration time than tablets lubricated with magnesium stearate-talc (MT) mixture but still falls within the acceptable limit of 15 minutes. Figure 3 shows the representative plots of disintegration time versus relative density at a concentration of $0.5 \% \mathrm{w} / \mathrm{w}, 1.5 \% \mathrm{w} / \mathrm{w}$, $2.5 \% \mathrm{w} / \mathrm{w}$ are shown this could be because since most lubricants are hydrophobic and they are usually in smaller sizes than any other ingredients in the tablet formulations. When the mixture is mixed, lubricant particles may adhere to the surface of the other particles, thus hydrophobic coating inhibits the wetting and consequently tablet disintegration.

\subsubsection{Crushing strength friability/disintegration ratio}

The crushing strength friability/disintegration time ratio (CSFR/DT ratio) has been suggested as a better index for measuring tablet strength (crushing) and weakness (friability). It simultaneously evaluates all negative effects on these parameters on disintegration time. A higher value of CSFR/DT ratio indicates a better balance between binding and disintegration properties. Thus, the higher the CSFR/DT values the better the disintegration of the tablet. From the values obtained as shown in Table 3.2, it was observed that the CRFR/DT for tablets containing goat fat- magnesium stearate-talc (GMT) mixture are lower than those containing magnesium stearate- talc (MT) mixture. From the plots of CSFR/DT versus relative density for paracetamol tablets containing $0.0 \% \mathrm{w} / \mathrm{w}$ and $2.5 \% \mathrm{w} / \mathrm{w}$ lubricant as shown in Figure 4 higher values of CSFR/DT obtained for tablets lubricated with magnesium-stearate implies that disintegration time values better than the tablets lubricated with goat fat-magnesium stearate-talc mixtureare obtained. This is because since goat fat is a lipid substance and which would simultaneously reduce the penetration of the disintegration fluid into the tablet mass while bridging the gap between the particles leading to increased bonding.

\section{CONCLUSION AND RECOMMENDATIONS}

From the present study, the use of goat fat as co-processed lubricant with magnesium stearate and talc in the formulation of paracetamol tablets has shown that goat fat enhances the packaging and flow properties of the paracetamol granules. The crushing strength and disintegration time of the tablets 
increased with increase in lubricant concentration with goat fat co-processed with magnesium stearate and talc having higher values. he crushing strength friability/disintegration time ratios (CSFR/DT) of the tablets reveals that the co-processed lubricants (GMT) had a lower CSFR/DT values than tablets with magnesium stearate and talc (MT). Goat fat, an inexpensive and easily available lipid, is an effective lubricant which can be co-processed with magnesium stearate and talc (GMT) for an efficient lubrication of granules and perhaps, subject to further investigations through the determination of the tablets' tensile strength and brittle fracture index, could be useful in reducing lamination and capping in formulations that are susceptible to these two defects of tablets. This study also shows that the co-processed lubricant (GMT) may still be useful as a lubricant in situations where a higher CSFR/DT i.e. lower disintegration time is required (because of the satisfactory disintegration times of the tablets produced) and in situations where a higher crushing strength and disintegration time is required e.g. in sustained release tablets.

\section{Acknowledgement}

Authors wish to acknowledge the immense support and contribution of the staff of the Dispensing laboratory, Department of Pharmaceutics and Pharmaceutical Technology, Faculty of Pharmacy, University of Uyo, Uyo for the success of this work.

\section{REFERENCES}

[1] Rawlings,E.A, Bentley's Textbook of Pharmaceutics $\left(8^{\text {th }}\right.$ Edition.Baillere Tyndal),Uk, 2004, pp 269-289.

[2] W. A. Strickland, T. Higuchi, L. W. Busse, The physics of tablet compression, .J. A.M Pharm. Ass, 49 1960, $35-40$.

[3] K. R. Komarek. Selecting binders and lubricants for agglomeration processes, J. Chemical Engineering, 74, 1967, 154-155.

[4] H. I. Silversher, Materials for lubrication, Applications.spec publ.sp- 3051, 1969, 199-239.

[5] F. Speradeo and G. De machi,.The role and mode of action of lubricants in tablet manufacture Boll.Chim Farm.115, 1976, 801-809.

[6] W. A. Strickland, A new look at tablet lubricants, Drug and cosmetic.Ind. 85, 1959:318.

[7] A. N'Diaye, V. Jannin, V. Berad, C. Andres, Y. Pourcelot, Comparative study of the lubricant performance of Compritol HDS ATO and Compritol 888 ATO: effect of polyethylene glycol behenate on lubricant capacity, Int. J. Pharm., 254, 2003, 263-269.

[8] H. Aoshima, A. Miyagisniam, Y. Nozawa, Y. Sadzuka, T. sonobe. Glycerin fatty acid esters as a new lubricant of tablets. Int. J. Pharm., 293 (1-2), 2005, 25-34.

[9] G.K. Bolhuis, A. J. Smallenbrek, C. F. Lerk, Interaction of tablet disintegrants and magnesium stearate during mixing: Effect of tablet disintegration, J. Pharm. Sci. 70, 1981, 1328-1330.

[10] L.E. Flores, R. L. Arellano, J.J.D. Esquivel, Lubricant susceptibility of cellactose and Avicel PH-200: a quantitative relationship, Drug Dev. Ind. Pharm. 26, 2000, 297-305.

[11] A. C. Eissen, G. K. Bolhuis, WLJ. Hinrichs, H. W. Frijlinks, Inullin as filler binder for tablets prepared by direct compression, J. Pharm. Sci. 15, 2002, 31-38.

[12] A. A. Adebolu and G. Alebiowu, Evaluation of Cocoa Butter as Potential Lubricant for Coprocessing in Pharmaceutical Tablets, J. Pharmc. Dev. And Tech., 13, 2008, 197-204.

[13] G. Alebiowu and A. A. Adeagbo, Disintegrant properties of a paracetamol tablet formulation lubricated with Co-processed lubricants, Farmacia, Vol. 57, 4, 2009, 500-510. 